\title{
Trial of Ga-doping on ZnO Nanoparticles by Thermal Treatment with $\mathrm{Ga}_{2} \mathrm{O}_{3}$ Nanoparticles
}

\author{
Toshiyuki Yoshida, ${ }^{\mathrm{a}, \dagger}$ Islam Md Maruful, ${ }^{\mathrm{b}}$ Yasuhisa Fujita ${ }^{\mathrm{a}}$ \\ a Graduate School of Natural Science and Technology, Shimane University, 1060 Nishikawatsu, Matsue, Shimane, 690-8504, Japan \\ ${ }^{\mathrm{b}}$ Interdisciplinary Graduate School of Science and Engineering, Shimane University, 1060 Nishikawatsu, Matsue, Shimane, 690-8504, Japan \\ ${ }^{\dagger}$ Corresponding author: yosisi@riko.shimane-u.ac.jp
}

Received: 11 October, 2019; Accepted: 21 January, 2020; Published: 6 February, 2020

Direct Ga-doping into $\mathrm{ZnO}$ nanoparticles (NPs) were tried by thermal treatment mixed with $\mathrm{Ga}_{2} \mathrm{O}_{3}$ particles. Residual $\mathrm{Ga}_{2} \mathrm{O}_{3}$ particles were completely removed by appropriate centrifugation process. To confirm the Ga-doping, variations of sheet resistances for sprayed NP-layers on glass substrates were investigated, showing successful and dramatic reduction from $\mathrm{G} \Omega \mathrm{sq}^{-1}$-order to sub-k $\Omega \mathrm{sq}^{-1}$. The minimum sheet resistance reached to $225 \Omega$ $\mathrm{sq}^{-1}$. From X-ray diffraction and X-ray photoelectron spectroscopy analyses, it can be concluded that $\mathrm{Ga}$ atoms diffused from $\mathrm{Ga}_{2} \mathrm{O}_{3}$ into $\mathrm{ZnO}-\mathrm{NPs}$ in the thermal treatment process, and some of them substituted for $\mathrm{Zn}$ atoms and were activated as donors.

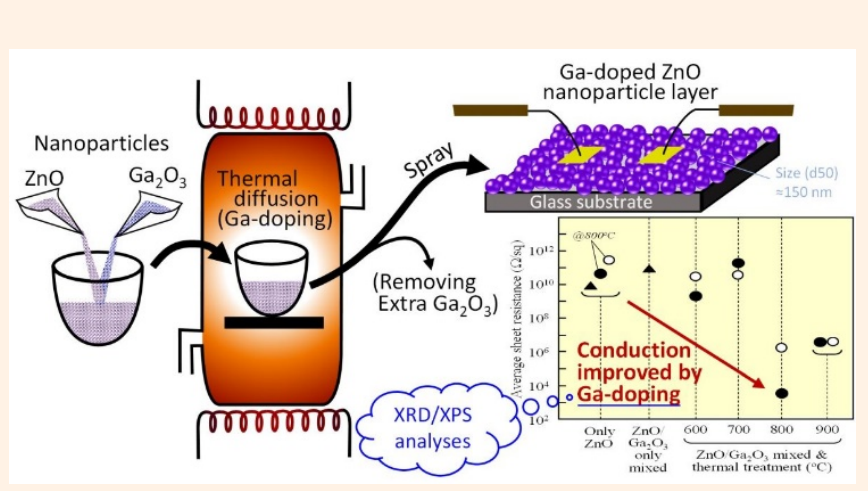
These results can contribute to continuous advance of $\mathrm{ZnO}-\mathrm{NP}$-based thin-film-transistor fabrication technique.

Keywords Zinc oxide; Nanoparticles; Ga-doping; Thermal diffusion; X-ray photoelectron spectroscopy

\section{INTRODUCTION}

Using semiconductor nanoparticle (NP) layers is one of the noticed methods to obtain channel layer of thin film transistors (TFTs) [1-5], because of its high selectivity of substrate materials and surface morphology, and its compatibility of the printing electronics, atmospheric processing, the low costing and the large area processing. Oxide semiconductors such as $\mathrm{ZnO}$ do not form an insulating layers at the NP surfaces when dispersed in water and/or handled in the air, which make it easy to TFT fabrication process. Therefore, many efforts have been made to form and demonstrate TFTs with the n-type ZnO-NP channels on various substrates [1, 6-12] including demonstration of the logic operations [13].

Recently, by using the ZnO-NPs synthesized in our laboratory $[14,15]$, not only n-channel but also p-channel back-gate TFTs on $\mathrm{Si} / \mathrm{SiO}_{2}$ substrates were successfully demonstrated by using the simple and easy spraying method [16], providing high expectation to realize complementary logic circuits using $\mathrm{ZnO}$-based NP-layers. However, the performances of obtained TFTs were insufficient. Most weak point is the extremely high resistivity of horizontal carrier transportation in the sprayed $\mathrm{ZnO}-\mathrm{NP}$ layers (order of $\mathrm{G} \Omega \mathrm{sq}^{-1}$ ). Such large parasitic resistances cause the significant degradation of the gain and switching speed in analog and digital operations, respectively. By simple estimation with assuming the logic gate capacitances of several $\mathrm{pF}$, even $100 \mathrm{~Hz}$ logic operation will be impossible using these TFTs. It is essential to reduce the sheet resistances of obtained ZnO-NP layers for TFT channel applications. Additionally, achieving direct doping into NPs is preferable rather than doping onto the NP-layers, because such doping processes after NP-layer formation should disturb the simplicity of the particle-base process and the selectivity of substrate materials.

In this study, direct Ga-doping was tried to the $\mathrm{ZnO}-\mathrm{NPs}$ synthesized in our laboratory by thermal treatment with $\mathrm{Ga}_{2} \mathrm{O}_{3}-\mathrm{NPs}$, and the resistivity reduction of sprayed $n-\mathrm{ZnO}$ NP-layers were verified.

\section{EXPERIMENTAL}

$\mathrm{ZnO}-\mathrm{NPs}$ were synthesized by arc-discharge-mediated 
gas evaporation method. The backpressure of main chamber was less than 0.3 Torr. Dry air was introduced with the rate of $5 \mathrm{~L} \mathrm{~min}^{-1}$, and the chamber pressure was regulated at 610 Torr by the regulating valve and the rotary pump through the synthesizing period. A metal Zn bulk (99.99\%) and a carbon rod were used as arc-discharging electrodes. Arc current was 20 A. From our previous study, it is known that the chamber pressure and the arc current are key conditions to control the introducing amount of nitrogen atoms in the obtained $\mathrm{ZnO}$ nanoparticles. Details are described in Refs. 14 and 16, in which n-type conductive particle was recommended. Thus, the conditions to obtain $\mathrm{ZnO}$ particles with less nitrogen doping were used.

Thermal treatments were applied to some of obtained $\mathrm{ZnO}$ nanoparticles with $\mathrm{Ga}_{2} \mathrm{O}_{3}$ particles (Sigma-Aldrich). Particles of $\mathrm{ZnO}(0.2 \mathrm{~g})$ and $\mathrm{Ga}_{2} \mathrm{O}_{3}(0.06 \mathrm{~g})$ were mixed in the crucible and heated in the electric furnace with the temperature of $600-900^{\circ} \mathrm{C}$ for $60 \mathrm{~min}$. In this study, two types of ambient gas were applied; one was the atmospheric air which was similar to the gas in NP-synthesizing, and the other was pure nitrogen which would expectedly generate the oxygen vacancies acting as native donors. In thermal treatment with the atmospheric air, the valve of the furnace was opened to the atmosphere and the fresh air (with humidity of about $60 \%$ ) was supplied by thermal convection. In case with pure nitrogen, the nitrogen gas with the dew point of less than $-60^{\circ} \mathrm{C}$ and the purity of $99.995 \%$ was supplied with the rate of $0.5 \mathrm{~L} \mathrm{~min}^{-1}$. In both case, the temperature was increased from RT to each setting values within $10 \mathrm{~min}$, and after $60 \mathrm{~min}$ thermal treatment, the samples were cooled down to less than $40^{\circ} \mathrm{C}$ in $2 \mathrm{~h}$.

The dispersions were prepared by dispersing $0.2 \mathrm{~g}$ of above mixed and thermally treated particles with $10 \mathrm{~g}$ of ultrapure water using ultrasonic homogenizer with the power of $150 \mathrm{~W}$ for $3 \mathrm{~min}$ and by following centrifuging with $3000 \mathrm{G}$ for $1 \mathrm{~min}$.

To form particle layers [16], $30 \mathrm{~mL}$ of dispersion fluid were sprayed to heated quartz substrates using standard airbrush, as shown in Figure 1, with 5-s intervals for $15 \mathrm{~min}$. The setting value of the hot plate temperature was $500^{\circ} \mathrm{C}$ (the actual surface temperature was about $370^{\circ} \mathrm{C}$ determined using thermographic measurement). The estimated thickness

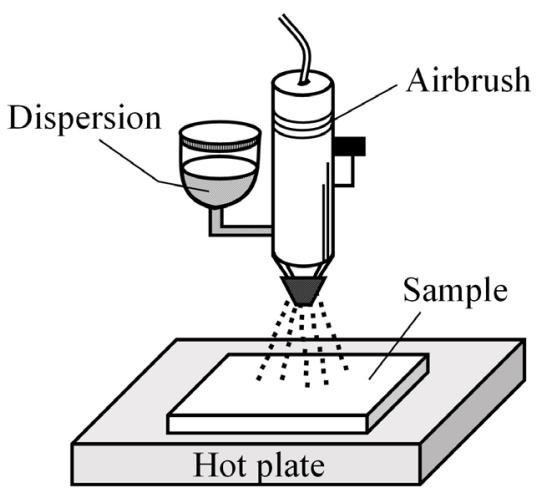

Figure 1: Schematic illustration of the spraying method. of particle layers were about $10 \mu \mathrm{m}$. Additional $\mathrm{Al} / \mathrm{Au}$ electrodes with the width and length of $0.3 \mathrm{~mm}$ were formed for $I-V$ measurements.

$I-V$ measurements to determine the variation of sheet resistances were performed using a shielding prover system and E5270B Precision measurement mainframe with E5287A Atto-level High Resolution SMU module (Keysight Technologies). Powder X-ray diffraction (XRD) (SmartLab, Rigaku Corporation, $\lambda=1.54 \AA$ ) was used for $2 \theta$-scan with scanning speed of $0.001 \%$ step. Elemental analyses were performed by X-ray photoelectron spectroscopy (XPS) with monochromatic $\mathrm{Al} \mathrm{K \alpha}$ radiation. The measurements were carried out on the surface of as-sprayed NP-layers without additional cleaning process. Binding energies were calibrated by shifting the $\mathrm{C} 1 \mathrm{~s}$ peak position to $285.0 \mathrm{eV}[17,18]$.

\section{RESULTS AND DISCUSSION}

$\mathrm{ZnO}$ and $\mathrm{Ga}_{2} \mathrm{O}_{3}$ particle size distributions are shown in Figure 2(a), which were prepared by dispersing each particles in ultrapure water by ultrasonic homogenizer without centrifugal separation procedure. The $\mathrm{ZnO}$ particles that were synthesized in our laboratory have a main peak at around $150 \mathrm{~nm}$ and a tail distribution over $1000 \mathrm{~nm}$. On the other hand, the $\mathrm{Ga}_{2} \mathrm{O}_{3}$ particles have sharp distribution with median size of $667 \mathrm{~nm}$. In Figure 2(b), the dispersions that contain $\mathrm{ZnO} / \mathrm{Ga}_{2} \mathrm{O}_{3}$ mixed and thermally treated particles

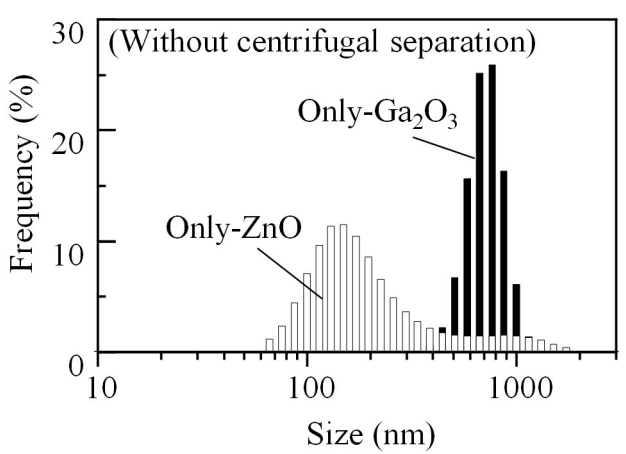

(a)

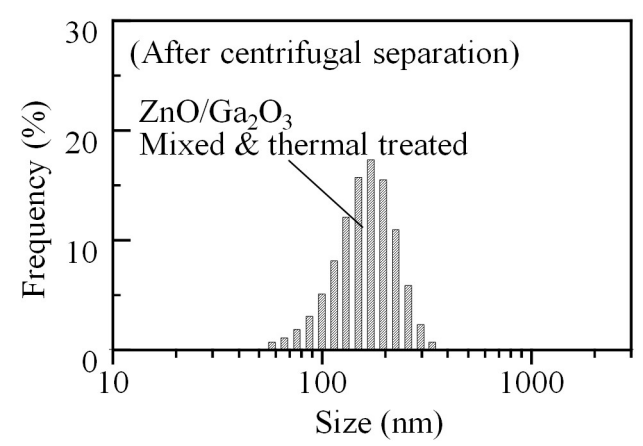

(b)

Figure 2: Particle size distributions for (a) separately measured $\mathrm{ZnO}$ and $\mathrm{Ga}_{2} \mathrm{O}_{3}$ nanoparticles without centrifugal separation and (b) mixed and thermally treated $\mathrm{ZnO}$ and $\mathrm{Ga}_{2} \mathrm{O}_{3}$ particles after centrifugal separation. 


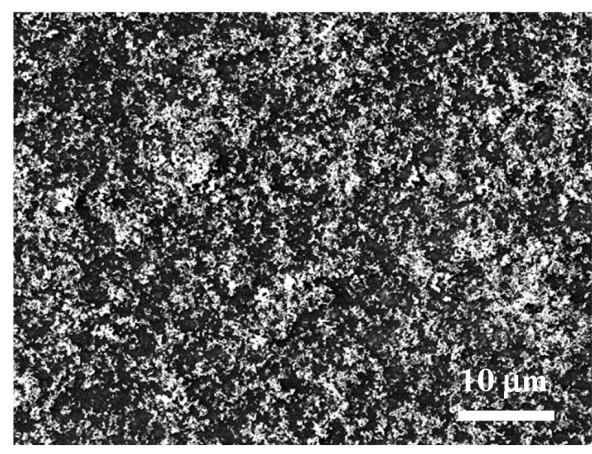

Figure 3: SEM image of the surface of quartz substrate after spraying procedure. Particles labeled "Only ZnO" in Figure 4 were used.

with centrifugal separation procedure show only a sharp distribution with a median size of $153 \mathrm{~nm}$. This result indicates that large $\mathrm{ZnO}$ particles and all $\mathrm{Ga}_{2} \mathrm{O}_{3}$ particles were removed by centrifuging, and only small sizes of $\mathrm{ZnO}$ particles remained in the dispersion fluid. By the spraying method, NP-layers were formed onto the quartz substrates. The scanning electron microscopy (SEM) image of the sprayed $\mathrm{ZnO}-\mathrm{NP}$ layer is shown in Figure 3, confirming the quartz surface was covered with NPs with less aggregation.

The sheet resistance variations among various kinds of particle layers used in this study are summarized in Figure 4, which were measured by two probe $I-V$ measurements with the voltage range from $-10 \mathrm{~V}$ to $+10 \mathrm{~V}$. The current flow area has a $300 \mu \mathrm{m} \times 300 \mu \mathrm{m}$ square shape, so the sheet resistance can be directly obtained from the slope of $I-V$ curves, and each point indicates the average value obtained from 6 to 10 measurements. The sprayed particle layers formed using as-prepared $\mathrm{ZnO}$ particles and only mixed with $\mathrm{Ga}_{2} \mathrm{O}_{3}$ particles (without thermal treatment) show very high sheet resistance in the order of $\mathrm{G} \Omega \mathrm{sq}^{-1}$. These data are labeled "Only $\mathrm{ZnO}$ " and " $\mathrm{ZnO} / \mathrm{Ga}_{2} \mathrm{O}_{3}$ only mixed", respectively, and are shown with filled triangles $(\boldsymbol{\Delta})$ in Figure 4.

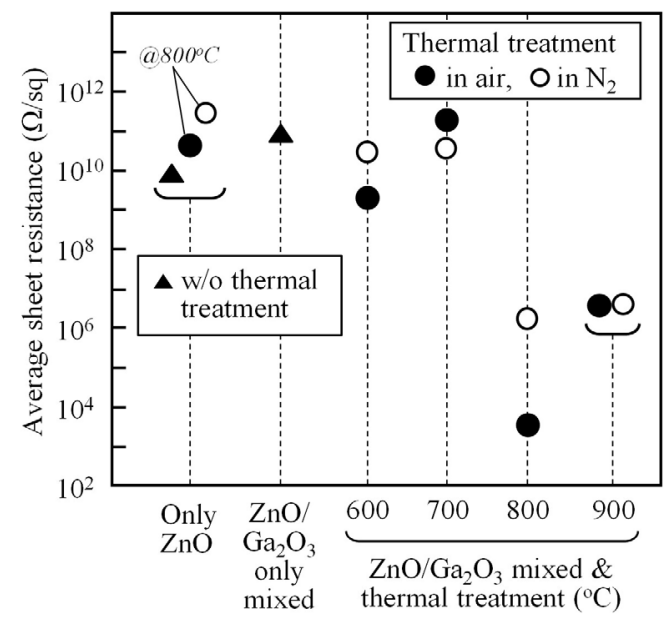

Figure 4: Sheet resistance variation of various kinds of particle layers used in this study measured by two-probe $I-V$ measurements.
Circular marks indicate the sheet resistance values for the samples using thermally treated particles; filled circles (O) indicate that the thermal treatments were carried out in atmospheric air and open circles $(O)$ in pure nitrogen. From these results, the temperature of thermal treatment less than $700^{\circ} \mathrm{C}$ had no effect to reduce the sheet resistance, meaning no reaction between mixed $\mathrm{ZnO}$ and $\mathrm{Ga}_{2} \mathrm{O}_{3}$ particles. On the other hand, thermal treatment with the temperature of $800^{\circ} \mathrm{C}$ and $900^{\circ} \mathrm{C}$ showed significant reduction of 4 to 7 orders of magnitude. Especially, the conditions of $800^{\circ} \mathrm{C}$ in atmos-

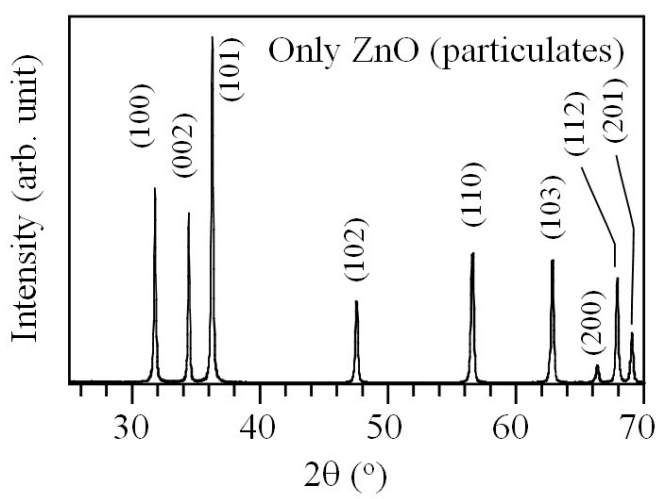

(a)

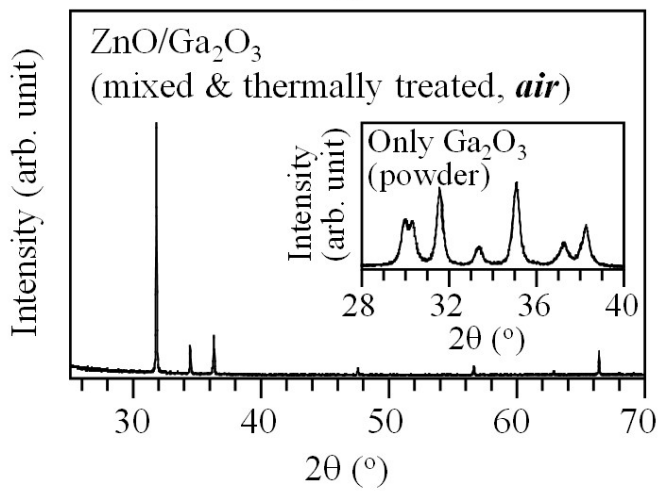

(b)

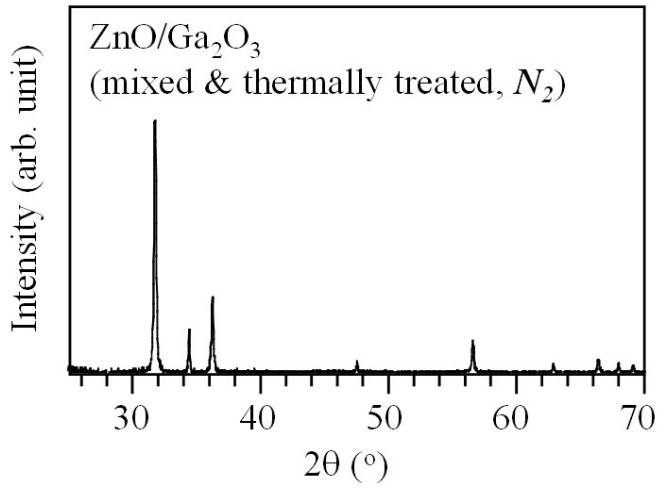

(c)

Figure 5: XRD results for (a) $\mathrm{ZnO}$ nanoparticles (particulates) and (b and c) NP-layers on quartz substrates sprayed with $\mathrm{ZnO} / \mathrm{Ga}_{2} \mathrm{O}_{3}$ mixed and thermally treated $\left(800^{\circ} \mathrm{C}\right)$ particles in air and $\mathrm{N}_{2}$, respectively. For (b and c), dispersion was prepared with centrifugal separation process. The inset in (b) shows the XRD spectra for $\mathrm{Ga}_{2} \mathrm{O}_{3}$ particles (particulates). 
pheric air are the most effective, and the minimum value reached $225 \Omega \mathrm{sq}^{-1}$. As a reference, the sheet resistances obtained using thermally treated "Only-ZnO" particles (at $800^{\circ} \mathrm{C}$ ) are also indicated in Figure 4, resulting no effect to reduce the sheet resistance. Thus, it is confirmed that the property of the $\mathrm{ZnO}$ particles had been influenced by mixing with the $\mathrm{Ga}_{2} \mathrm{O}_{3}$ particles and thermally treating with a temperature over $800^{\circ} \mathrm{C}$.

Figure 5 shows XRD results for $\mathrm{ZnO}$ nanoparticles (particulates) and NP-layers sprayed with $\mathrm{ZnO} / \mathrm{Ga}_{2} \mathrm{O}_{3}$ mixed and thermally treated $\left(800^{\circ} \mathrm{C}\right)$ particles in the air and $\mathrm{N}_{2}$. From Figure 5(a), generally known peaks of the $\mathrm{ZnO}$ particles with single crystalline state [19-21] were obtained. All these peaks were observed after the thermal treatment and spraying procedures as shown in Figure 5(b), however, the intensity ratio changed. The signals from the (100) and (200) planes are dominant, i.e., hexagonal column structured particles laid with the column face up (m-plane) by the spraying procedure. In Figure 5(a, b), full-width at half-maximum (FWHM) values were changed from $0.20^{\circ}$ to $0.08^{\circ}$ for the (100) peaks by thermal treatment in the air. Using Scherrer's equation and the crystallite-effect-less FWHM value of $0.08^{\circ}$ in this XRD system, the size of crystallite changed from $45 \mathrm{~nm}$ to more than $100 \mathrm{~nm}$ by the thermal treatment in the air, while it was changed only to $55 \mathrm{~nm}$ [the FWHM of $0.17^{\circ}$ from Figure 5(c)] by the thermal treatment in $\mathrm{N}_{2}$. On the other hand, the $\mathrm{Ga}_{2} \mathrm{O}_{3}$ particles used in this study provided XRD peaks as shown in the inset of Figure 5(b). These peaks are consistent with previous results of the $\beta-\mathrm{Ga}_{2} \mathrm{O}_{3}$ particles [22]. But there were no $\mathrm{Ga}_{2} \mathrm{O}_{3}$-related peaks in Figure 5(b, c). It is confirmed, again, that almost of the $\mathrm{Ga}_{2} \mathrm{O}_{3}$ particles were removed by the centrifugal separation process.

To discuss about the sheet resistance reductions, XPS spectra were analyzed. Figure 6(a) shows Ga 3d spectra for sprayed particle layers made of $\mathrm{ZnO} / \mathrm{Ga}_{2} \mathrm{O}_{3}$ mixed with and without centrifugal separation process (no thermal treatment), $\mathrm{ZnO} / \mathrm{Ga}_{2} \mathrm{O}_{3}$ mixed and thermally treated at $800^{\circ} \mathrm{C}$ in the air and $\mathrm{N}_{2}$ with centrifugal separation and, as a reference, only $\mathrm{ZnO}$. Overlapping $\mathrm{O} 2 \mathrm{~s}$ spectra are also shown. The peak intensities were normalized with those of the $\mathrm{Zn} \mathrm{3d}$ spectra, as shown in the inset of Figure 6(a). Also, the peak positions were shifted to adjust $\mathrm{Zn} 3 \mathrm{~d}$ at $10.0 \mathrm{eV}$. So, the horizontal axis indicates the energy difference from the $\mathrm{Zn}$ $3 \mathrm{~d}$ peak. Here, the shifts of energy positions were within $\pm 0.1 \mathrm{eV}$. The $\mathrm{Ga} 3 \mathrm{~d}$ spectrum obtained from $\mathrm{ZnO} / \mathrm{Ga}_{2} \mathrm{O}_{3}$ mixed without centrifugal separation shows the largest intensity because all $\mathrm{Ga}_{2} \mathrm{O}_{3}$ particles remained, but after centrifugal separation, only the slight $\mathrm{Ga} 3 \mathrm{~d}$ component was observed. This again indicates the residual $\mathrm{Ga}_{2} \mathrm{O}_{3}$ particles can be removed by the suitable centrifugal separation process throughout this study. On the other hand, a relatively large $\mathrm{Ga} 3 \mathrm{~d}$ peak was observed from $\mathrm{ZnO} / \mathrm{Ga}_{2} \mathrm{O}_{3}$ mixed and thermally treated $\left(800^{\circ} \mathrm{C}\right)$ both in the air and $\mathrm{N}_{2}$, in spite of processed with centrifugal separation. This strongly suggests that $\mathrm{Ga}$ atoms diffused from $\mathrm{Ga}_{2} \mathrm{O}_{3}$ into the $\mathrm{ZnO}$ particles in the thermal treatment process at $800^{\circ} \mathrm{C}$. Another analysis on
O 1s spectra was carried out as shown in Figure 6(b). In this figure, (A) $\mathrm{ZnO} / \mathrm{Ga}_{2} \mathrm{O}_{3}$ and (B) only $\mathrm{ZnO}$ particles with thermal treatment $\left(800^{\circ} \mathrm{C}\right.$, air) and centrifugal separation were compared. The intensities are normalized, and the difference "(A)-(B)" is shown. The main peak at $530.5 \mathrm{eV}$ is assigned to wurtzite $\mathrm{ZnO}$, and the tail part at the higher binding energy is usually explained by $\mathrm{V}_{\mathrm{O}}$ and/or $\mathrm{OH}$ group with a chemical shift of over $1.5 \mathrm{eV}$ [23-25]. Here, the difference "(A)-(B)" shows an energy difference of about 0.8 $\mathrm{eV}$. In both samples, the condition difference is only the ex-

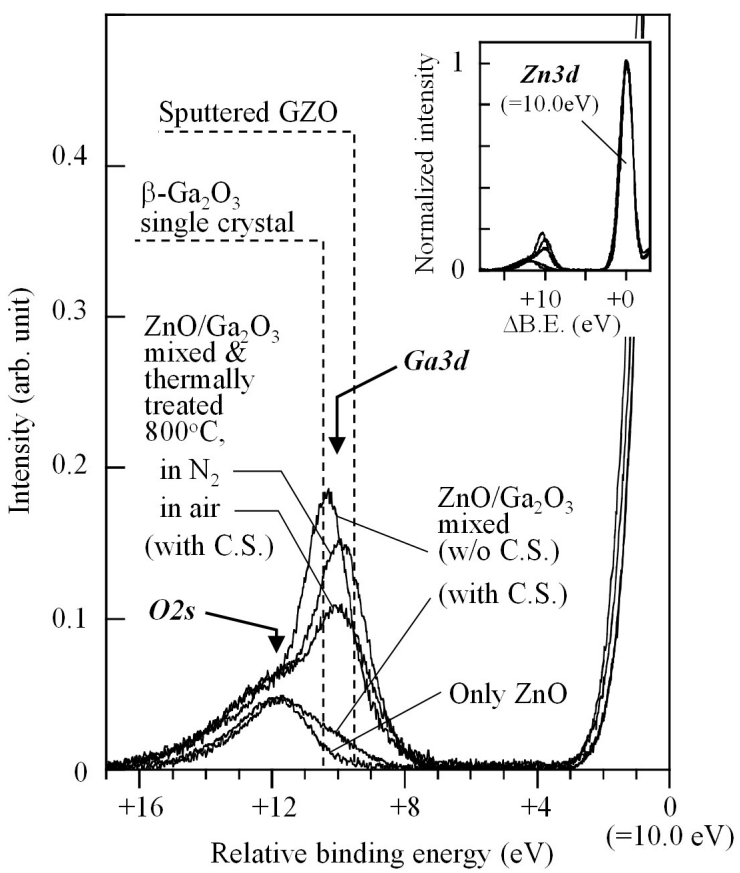

(a)

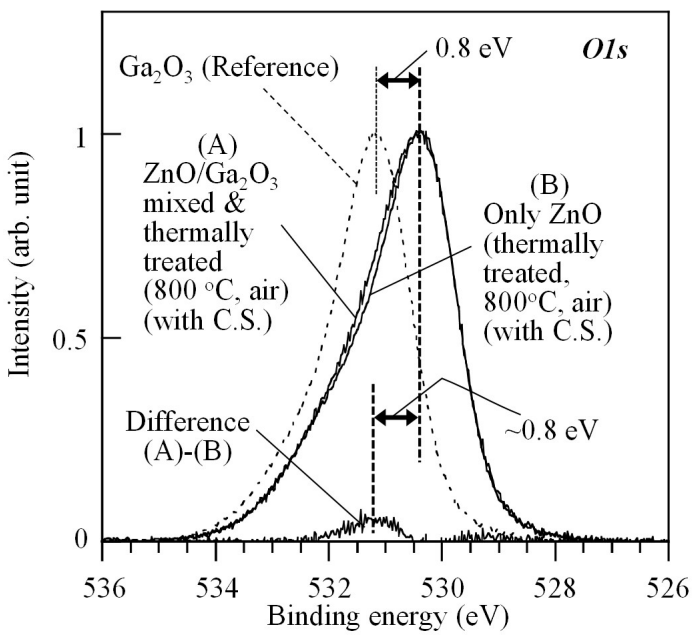

(b)

Figure 6: (a) XPS Ga 3d spectra for various samples. The peak position and intensity were normalized with the $\mathrm{Zn} 3 \mathrm{~d}$ peak. The inset shows the overall spectra of $\mathrm{Zn}$ and $\mathrm{Ga} 3 \mathrm{~d}$. (b) Comparison of XPS O1s spectra between particle layers using thermally treated only- $\mathrm{ZnO}$ and $\mathrm{ZnO} / \mathrm{Ga}_{2} \mathrm{O}_{3}$-mixed particles. As a reference, $\mathrm{Ga}_{2} \mathrm{O}_{3}$ $\mathrm{O} 1 \mathrm{~s}$ spectrum is also shown. (C.S. : centrifugal separation) 
istence of $\mathrm{Ga}_{2} \mathrm{O}_{3}$ particles in the thermal treatment process, and they were removed by following centrifugal separation. Considering the fact that the difference between the $\mathrm{O} 1 \mathrm{~s}$ spectra of $\mathrm{O}-\mathrm{Zn}$ and $\mathrm{O}-\mathrm{Ga}$ is $0.8 \mathrm{eV}$ which can be determined using the $\mathrm{O}$ 1s spectrum of $\mathrm{Ga}_{2} \mathrm{O}_{3}$ shown in Figure $6(\mathrm{~b})$ as a reference, the difference "(A)-(B)" indicates the new component caused by the $\mathrm{Ga}$ incorporation into $\mathrm{ZnO}-\mathrm{NPs}$.

Using the molecular weights of $\mathrm{ZnO}$ and $\mathrm{Ga}_{2} \mathrm{O}_{3}$ and the intensity ratios of the $\mathrm{Ga} 3 \mathrm{~d}$ or $\mathrm{O} 1 \mathrm{~s}$ spectrum, the estimated $\mathrm{Ga}$ amount in NP-layer of " $\mathrm{ZnO} / \mathrm{Ga}_{2} \mathrm{O}_{3}$ mixed and thermally treated $\left(800^{\circ} \mathrm{C}\right.$, air)" is about $5-7$ at $\%$ with assuming a uniform $\mathrm{Ga}$ distribution. If this estimate is correct, the measured resistance in Figure 4 should be one or two orders of magnitude smaller. The reason why so much $\mathrm{Ga}$ was detected in Figure 6 can be considered that diffused Ga was mainly distributed near the surface of the $\mathrm{ZnO}$ particles, increasing the effective irradiated area by X-ray and emphasizing the apparent intensity of the Ga $3 \mathrm{~d}$ and Ga-related $\mathrm{O}$ 1s signals. From Figure 6(a), a thermal treatment in $\mathrm{N}_{2}$ caused a larger Ga signal, which can be explained using the smaller particulate size estimated by XRD. The smaller size gave the larger surface and/or grain-boundary-like sites to distribute the diffused Ga atoms. This can support the above assumption, however, further consideration is difficult at this stage. Anyway, it can be concluded that the Ga atoms diffused into the ZnO-NPs by the thermal treatment, and, because of following reasons, a part of them certainly substituted for the $\mathrm{Zn}$ atoms and were activated as donors.

One reason is the difference in the peak position of the $\mathrm{Ga}$ $3 \mathrm{~d}$ spectra. In Figure 6(a), the obtained $\mathrm{Ga} 3 \mathrm{~d}$ peak positions from $\beta-\mathrm{Ga}_{2} \mathrm{O}_{3}(100)$ single crystal substrate $(20.5 \mathrm{eV}$, i.e., $+10.5 \mathrm{eV}$ from $\mathrm{Zn} \mathrm{3d}$ ) and a sputtered Ga-doped $\mathrm{ZnO}$ (GZO) film (19.6 eV, i.e., $+9.6 \mathrm{eV})$ are also shown. Generally, the $\mathrm{Ga}$ atoms in the GZO film are activated with substituting for the $\mathrm{Zn}$ atoms, which will cause the variation of a chemical bonding state and the difference of the peak position in the Ga-related spectra. In the case of " $\mathrm{ZnO} / \mathrm{Ga}_{2} \mathrm{O}_{3}$ mixed (without centrifugal separation)", all of the $\mathrm{Ga} 3 \mathrm{~d}$ signal originated from the mixed $\mathrm{Ga}_{2} \mathrm{O}_{3}$ particles, naturally showing a similar peak position with that of the $\beta-\mathrm{Ga}_{2} \mathrm{O}_{3}$ single crystal. On the other hand, in the case of " $\mathrm{ZnO} / \mathrm{Ga}_{2} \mathrm{O}_{3}$ mixed \& thermally treated $\left(800^{\circ} \mathrm{C}\right.$, with centrifugal separation) in $N_{2}$ and in the air", the peak position shifted towards lower binding energies tending to that of the GZO film. However, the peak position is not the same as that of the GZO film, suggesting that some of the diffused Ga atoms substituted for the $\mathrm{Zn}$ atoms.

The other reason is a lattice constant variation. The estimated lattice constants using the Bragg's law on the hexagonal system and the accurate peak positions of XRD (002) signals are $5.2057 \AA\left(2 \theta=34.415^{\circ}\right)$ and $5.2044 \AA(2 \theta=$ $34.424^{\circ}$ ) from Figures 5(a) and 5(b), respectively, i.e., about a $0.001-\AA$ reduction was observed after the thermal treatment with the $\mathrm{Ga}_{2} \mathrm{O}_{3}$ particles. Generally, the lattice constant will be reduced by the substitution of $\mathrm{Ga}(0.47 \AA)$ for $\mathrm{Zn}$ $(0.60 \AA)$ because of a smaller ion radius [26]. In our case, the observed change was small but this can also explain that some of the diffused $\mathrm{Ga}$ atoms substituted for the $\mathrm{Zn}$ atoms.

From the XRD and XPS analyses, direct Ga-doping to $\mathrm{ZnO}-\mathrm{NPs}$ by simple mixing and thermal treating with $\mathrm{Ga}_{2} \mathrm{O}_{3}$ particles was confirmed, which reduced the resistivity of the sprayed ZnO NP-layers dramatically.

Finally, as described in Sec. II, it was expected that the thermal treatment in pure $\mathrm{N}_{2}$ tended to generate more defects comparing that in the open air, which would act as native donors improving the conductance. However, the obtained sheet resistances tended to show the opposite behavior. One possible reason is that the oxygen vacancies were generated mainly at the surfaces of NPs, which cannot contribute to generation of carriers different from the bulk. Another possible reason is that the defects were not generated as expected. Recent photoluminescence analyses (not shown here) support the latter case, i.e., the thermal treatment in the pure $\mathrm{N}_{2}$ ambient lead less defects comparing with that in the open air. Controlling of the defects is important for the diffusion and the substitution behaviors, so it needs continuous investigation about the defect properties on $\mathrm{ZnO}-\mathrm{NPs}$ to achieve more effective Ga-doping.

\section{CONCLUSIONS}

From detail analyses in the XRD and XPS results, expected Ga-doping on $\mathrm{ZnO}-\mathrm{NPs}$ was confirmed by mixing and thermally treating with $\mathrm{Ga}_{2} \mathrm{O}_{3}$ particles, resulting dramatic reduction of the sheet resistances of the sprayed $\mathrm{n}-\mathrm{ZnO}$ NP-layers successfully. Dependence of the temperature and the ambient gas (air and $\mathrm{N}_{2}$ ) in the thermal treatment upon the sheet resistance was also shown.

\section{Acknowledgments}

The authors wish to acknowledge Dr. T. Hashizume, a professor of Hokkaido University and Dr. M. Akazawa, an associate professor of Hokkaido University for providing the XPS measurement system and their useful comments. The authors also wish to acknowledge the cooperation of Centre for Integrated Research in Science, Shimane University, for providing the SEM and XRD measurement systems. This work was supported by JSPS KAKENHI Grant No. 16K06263.

\section{References}

[1] A. K. Diallo, M. Gaceur, S. Fall, Y. Didane, S. B. Dkhil, O. Margeat, J. Ackermann, and C. V.-Ackermann, Mater. Sci. Eng. B 214, 11 (2016).

[2] Y.-H. Kim, E. Y. Lee, H. H. Lee, and T. S. Seo, ACS Appl. Mater. Interfaces 9, 16375 (2017).

[3] J. Choi, J. Yun, K. Cho, and S. Kim, Jpn. J. Appl. Phys. 53, 08NE02 (2014).

[4] Z. Meric, C. Mehringer, M. P. M. Jank, W. Peukert, and L. Frey, MRS Adv. 1, 2331 (2016).

[5] S. C. Lim, J. Y. Oh, J. B. Koo, C. W. Park, S.-W. Jung, B. S. Na, and H. Y. Chu, J. Nanosci. Nanotechnol. 14, 8665 (2014). 
[6] T. Yoshida, K. Shinohara, D. Itohara, and Y. Fujita, e-J. Surf. Sci. Nanotechnol. 14, 175 (2016).

[7] M. S. Rajachidambaram, T. Varga, L. Kovarik, R. Sanghavi, V. Shutthanandan, S. Thevuthasan, S.-Y. Han, C.-H. Chang, and G. S. Herman, J. Vac. Sci. Technol. B 30, 041805 (2012).

[8] N. Mechau, S. Bubel, D. Nikolova, and H. Hahn, Phys. Status Solidi A 207, 1684 (2010).

[9] S. Walther, S. Polster, M. P. M. Jank, H. Thiem, H. Ryssel, and L. Frey, Adv. Power Technol. 22, 253 (2011).

[10] H. Faber, M. Klaumünzer, M. Voigt, D. Galli, B. F. Vieweg, W. Peukert, E. Spiecker, and M. Halik, Nanoscale 3, 897 (2011).

[11] H.-C. Huang and T.-E. Hsieh, Nanotechnology 21, 295707 (2010).

[12] S. Lee, Y. Jeong, S. Jeong, J. Lee, M. Jeon, and J. Moon, Superlattices Microstruct. 44, 761 (2008).

[13] F. F. Vidor, T. Meyers, and U. Hilleringmann, Nanomatererials 6, 154 (2016).

[14] Y. Fujita, K. Moriyama, Y. Hiragino, Y. Furubayashi, H. Hashimoto, and T. Yoshida, Phys. Status Solidi C 11, 1260 (2014).

[15] K. Senthilkumar, T. Yoshida, and Y. Fujita, J. Mater. Sci. 53, 11977 (2018).

[16] D. Itohara, K. Shinohara, T. Yoshida, and Y. Fujita, J. Nanomater. 2016, 8219326 (2016).

[17] V. I. Nefedov, Y. V. Salyn, G. Leonhardt, and R. Scheibe, J. Electron Spectros. Relat. Phenomena 10, 121 (1977).

[18] O. Lupan, G. A. Emelchenko, V. V. Ursaki, G. Chai, A. N. Redkin, A. N. Gruzintsev, I. M. Tiginyanu, L. Chow, L. K. Ono, B. R. Cuenya, H. Heinrich, and E. E. Yakimov, Mater. Res. Bull. 45, 1026 (2010).

[19] J. R. Jensen, T. Johannessen, S. Wedel, and H. Livbjerg, J. Nanopart. Res. 2, 363 (2000).
[20] S.-M. Liu, F.-Q. Liu, H.-Q. Guo, Z.-H. Zhang, and Z.-G. Wang, Phys. Lett. A 271, 128 (2000).

[21] A. A. Azab, E. E. Ateia, and S. A. Esmail, Appl. Phys. A 124, 469 (2018).

[22] J.-J. Shan, C.-H. Li, J.-M. Wu, J.-A. Liu, and Y.-S. Shi, Ceram. Int. 43, 6430 (2017).

[23] N. Tabet, M. Faiz, and A. Al-Oteibi, J. Electron Spectros. Relat. Phenomena 163, 15 (2008).

[24] T. V. Richter, F. Stelzl, J. Schulz-Gericke, B. Kerscher, U. Würfel, M. Niggemann, and S. Ludwigs, J. Mater. Chem. 20, 874 (2010).

[25] L. G. Mar, P. Y. Timbrell, and R. N. Lamb, Thin Solid Films 223, 341 (1993).

[26] H. Gómez and M. de la L. Olvera, Mater. Sci. Eng. B 134, 20 (2006).

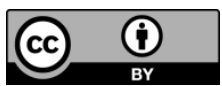

All articles published on e-J. Surf. Sci. Nanotechnol. are licensed under the Creative Commons Attribution 4.0 International (CC BY 4.0). You are free to copy and redistribute articles in any medium or format and also free to remix, transform, and build upon articles for any purpose (including a commercial use) as long as you give appropriate credit to the original source and provide a link to the Creative Commons (CC) license. If you modify the material, you must indicate changes in a proper way.

Published by The Japan Society of Vacuum and Surface Science 